\title{
Chickpea: No More a Recalcitrant Species for in vitro Regeneration Response
}

\author{
Suma S. Biradar $^{1 *}$, O. Sridevi ${ }^{1}$, P.M. Salimath ${ }^{2}$, P.U. Krishnaraj ${ }^{3}$, S.A. Desai ${ }^{1}$, \\ V. Rudra Naik ${ }^{1}$, Guruprasad Hiremath ${ }^{1}$ and B.A. Veeresha ${ }^{1}$ \\ ${ }^{1}$ Department of Genetics and plant breeding, UAS, Dharwad-580005, Karnataka, India \\ ${ }^{2}$ UAS, Raichur, Karnataka, India \\ ${ }^{3}$ Institute of Agricultural biotechnology, UAS, Dharwad-580005, Karnataka, India \\ *Corresponding author
}

A B S T R A C T

Keywords

Chickpea, Axillary meristem explants, Rooting, Recalcitrant.

Article Info

Accepted:

04 October 2017

Available Online:

10 December 2017
In the present investigation, various factors influencing in vitro response were studied to develop an efficient reproducible regeneration protocol. Culture conditions for various stages of adventitious shoot regeneration including the induction, elongation and rooting of the elongated shoots were optimized. All the three genotypes exhibited varied response to explant type, kind and concentration of growth regulators and also recorded high degree of interaction effect. Apart from the shoot number, regeneration of quality shoots was considered by using combination of cytokinins. Good success was achieved for root regeneration and establishment of seedlings. Thus, the present study open ups the new horizons for genetic manipulation of recalcitrant pulse crops like chickpea through biotechnological interventions.

\section{Introduction}

Chickpea is one of the important grain legumes, known for its rich protein content and hence, plays a significant role in the nutrition of rural and urban poor in the developing world. Therefore, the crop is known as "rich man's vegetable and poor man's meat". The crop is traditionally grown in many parts of the world, including Asia, Africa, Europe and North and South America, but the bulk of it is produced and consumed in South Asia and increasingly, the Middle East and some Mediterranean countries (Jodha and Subbarao, 1987). It is cultivated worldwide on more than 12 million ha (Rozan AlTanbouz and Hassan Abu-Qaoud, 2016).
However, the productivity of chickpea has not improved considerably over the years (Singh and Kataria, 2012). In spite of India being leading producer and consumer of chickpea, it is second in position for import value with a share of 14.1 per cent of total imports. Unlike cereal crops, chickpea yields worldwide have risen by only $80 \mathrm{~kg} \mathrm{ha}^{-1}$ and its area has remained virtually stagnant.

There are several significant and refractory constraints to chickpea production, which include both biotic and abiotic stress. To stabilize chickpea yield levels, there is a need to enhance insect and disease resistance in 
chickpea which can increase per capita availability of chickpea by as much as three times. Despite of concentrated breeding efforts, there is no much success towards resistance breeding. Recently, new biotechnological tools have complemented conventional breeding and promised success in several crops. Unlike other crops, chickpea is less amenable for genetic manipulation due to its recalcitrance response to in vitro regeneration. Regeneration in chickpea has been reported through organogenesis from various kinds of explants viz., shoot meristems (Kartha et al., 1981), cotyledonary node (Rekha and Thiruvengadam, 2009), shoot tips (Rozan Al-Tanbouz and Hassan Abu-Qaoud, 2016) and through embryogenesis from immature cotyledons (Sagare et al., 1993) and leaf let callus (Kumar et al., 1994). However, very few studies reported success with high frequency (Jayanand et al., 2003). The less success is observed to be due to the shoot formation from pre-existing meristems, making protocol inefficient for genetic transformation. Even such protocols tried by many scientists and were found to be non-reproducible in other laboratories (Fontana et al., 1993; Kar et al., 1997; Krishnamurthy et al., 2000). This necessitates the standardization of regeneration protocol which is highly repeatable. In the present study, efforts were made to explore different kind of tissue which is very much compatible with transformation protocol. We also tried to study major factors influencing shoot regeneration and came out with rigorous shoot regeneration and reproducible protocol. This off course pays the way for genetic manipulation of chickpea for agronomic and disease resistance improvement.

\section{Materials and Methods}

Three popular chickpea cultivars had chosen, of which two belonged to desi group viz., Annigeri-1, GBS-963 and ICCV-2 to kabuli group. These cultivars widely cultivated in Karnataka state, are highly susceptible to pod borer. Seed materials obtained from Department of Genetics and Plant breeding, UAS, Dharwad, were surface sterilized with $70 \%$ (v/v) ethanol for 1 minute, $0.1 \%$ mercuric chloride (w/v) for $4 \mathrm{~min}$ and rinsed 5 times with sterile distilled water prior to soaking overnight. Two different media one plain half MS and other MS medium supplemented with $4 \mu \mathrm{M}$ TDZ, $10 \mu \mathrm{M}$ 2-ip and $2 \mu \mathrm{M}$ KIN were employed for the germination of seeds. Better results were obtained with later medium (data not presented) and hence, used for standardization of regeneration protocol.

\section{Media and culture conditions}

Various media used during different stages of plant regeneration were shoot induction medium (SIM), shoot elongation medium (SEM) and root induction medium (RIM).

\section{Explant preparation}

In the present investigation, two explants viz., cotyledonary node $(\mathrm{CN})$ and axillary meristem explants (AME) were employed. Seven-day-old seedlings obtained from half MS medium were used for preparation of cotyledonary node explant by carefully removing shoot, root, axillary shoots and two cotyledons. This resulted in one $\mathrm{CN}$ explant per seedling of about $1 \mathrm{~cm}$ in size (Jayanand et al., 2003).

\section{Induction of multiple shoots}

$\mathrm{CN}$ explant was cultured for one month and then observation on number of multiple shoot buds produced were noted down. While, AMEs were grown for 1 week on SIM and then induced multiple shoots were allowed to grow for 7-10-days on MS medium before transfer to the SEM. 


\section{Elongation}

The explants having multiple shoot buds were sub cultured on SEM1 (MS $+5 \mu \mathrm{M} 2$-iP + $2 \mu \mathrm{M}$ kinetin) for 10 days while, un-elongated shoot buds sub cultured for two to three passages on SEM2 (MS $+2 \mu \mathrm{M}$ GA) at 7 days intervals. Placing of stunted shoot buds on SEM 2, resulted in increased intermodal length and frequency of elongated shoots. Shoots elongated to $5 \mathrm{~cm}$ in each passage were subjected to rooting.

\section{Induction of roots}

The well elongated healthy shoots with dark green leaves less than $5 \mathrm{~cm}$ in length were employed for standardization of rooting. The individual shoots carefully separated out from multiple shoot bunch were cultured in culture tubes containing filter paper bridges immersed in liquid root induction medium (RIM) that consisted of $1 / 2 \mathrm{MS}$ with modified levels of KNO3 $(9.4 \mathrm{mM})$ and various levels of NAA. Twenty shoots were used per treatment with two replications. The percent rooting was calculated in terms of the number of shoots responded, number of root lets and roots produced after ten to fifteen days of inoculation. Care was taken to observe root and shoot morphology in each treatment. Before subjecting of complete regenerated plants to hardening process, shoots were cultured on liquid Arnon's medium for 10-15 days to enhance root production and growth. Thus, obtained healthy seedlings were transferred to $10 \mathrm{~cm}$ diameter pots containing potting mixture.

\section{Hardening}

The hardening process started with the loosening and then removal of cotton plugs from the culture tubes for two-days. Thereafter, the plants which attained sufficient root growth were carefully taken out of the tube, thoroughly washed and transferred to $6 \mathrm{~cm}$ diameter pots containing vermiculite. Humidity was created by covering the plants with transparent polypropylene bags and allowed to grow for 10-15-days. The plants were exposed to the ambient conditions gradually by pinching holes and cutting the corners of the polypropylene bags. Plants were watered as and when required. Well grown plants were carefully transferred to a $20 \mathrm{~cm}$ diameter pots containing sterilized potting mix maintained at green house. The potting mix comprised a mixture of smooth and coarse sand mixed with black farm soil (3:2) with 10 percent organic matter.

\section{Statistical analysis}

Data from different explants and different media combinations obtained from similar experiments were pooled. The pooled data was analyzed as a factorial experiment (Gomez and Gomez, 1984). Further to study the effect of growth regulators on explant, genotype for shoot bud induction across the three cultivars, 'contrast' statistical device was adopted, which allow testing the specific group of means within an experiment. Contrast allows us to test specific hypothesis within an experiment. The means of the groups are tested based on the significance of each contrast (Sundararaj and Nagaraju 1968).

\section{Results and Discussion}

Chickpea being recalcitrant species for in vitro response needs standardization for genotype, growth regulator and explant. Even though some studies indicated success of in vitro shoot regeneration, but failed to obtain roots and suffered from reproducibility etc. These problems posed the chickpea crop less amenable for genetic engineering. Considering these points in view, attempts 
made in this direction, presents strong proof that recalcitrant crop like chickpea can also be successfully regenerated.

In the first phase of the study, the factors influencing shoot regeneration were dissected out by forming contrasts based on kind and combination of growth regulator, explant type and genotype. The results indicated that multiple shoot production is greatly influenced by all these factors (Table 1 and Fig. 1). Thus, it suggests the need for standardization of each factor to harvest maximum multiple shoots in chickpea.

\section{Effect of explant on shoot induction}

Explant, the basic input for regeneration of shoots, decides the number of multiple shoots to be produced. The type of the explant is determined by the kind of tissue, undifferentiated mass of cells and the preparation of explant itself. Regeneration potentiality of explant is further decided by the accessibility of undifferentiated mass of cells to growth regulators. In many of the earlier studies, shoot and leaf derived explants employed were having high percentage of differentiated mass of cells which resulted in very shy response for shoot regeneration. In some studies regeneration was achieved with leaf explants only (Rozan Al-Tanbouz and Hassan Abu-Qaoud, 2016). As an improvement over these, the use of cotyledonary node explant having undifferentiated tissue did not produce more than twelve shoots (Table 2). Another main drawback associated with the cotyledonary node explant is the absence of proliferating meristematic tissue. These drawbacks were taken care in case of axillary meristem explant (AME), which differed from the former for not having axillary buds.

A comparison of shoot morphogenetic potentiality of two explants revealed wide variation in the number of shoots per each type of explant. AME has maximum regeneration potential (14.21) compared to cotyledonary node (7.2) (Table 4). Apart from the type of explant, significant interaction effect for explant and growth regulator was observed. The cotyledonary node produced 11.25 shoots per explant at $0.25 \mathrm{mg} / \mathrm{L}$ TDZ. In contrast, AME exhibited multifold increase in shoot number (24.35) with cytokinin combinations as compared to TDZ alone which revealed an enormous organogenetic potentiality of axillary meristem explant.

This difference can be attributed to the production of fresh meristematic cells and presence of cotyledon in the AME. From the study, it is evident that the presence of cotyledons is essential for realizing maximum shoot production potential (Jayanand et al., 2003). However, CN explant exhibited better response among the different types of explants with most of the growth regulator combinations and concentrations (Sharma and Amla, 1998). Aasim et al., (2010) showed that cotyledon node was more responsive when compared to hypocotyl explants.

\section{Effect of growth regulators on multiple shoot regeneration}

The results of various concentrations of TDZ along with its combination with other growth regulators are shown in Table 3 . Increase in TDZ level in general resulted in higher multiple shoots however, beyond $0.4 \mathrm{mM}$ drastically reduced the shoot number per responding explant in case of A-1 and ICCV2. Higher concentration of TDZ had negative effect on regeneration, and resulted in stunted growth of shoot buds and even they failed to elongate (Rajendrer-Singh et al., 2002). Higher concentration of TDZ also found reduced growth and shoots proliferation at higher concentration of TDZ. In the presence of TDZ, similar deformities have been reported in many crops (Burkhanova et al., 1984; Murthy et al., 1996; Saxena et al., 1992 
and Varga et al., 1990). Rozan Al-Tanbouz and Hassan Abu-Qaoud (2016) observed shoot regeneration when lower levels of TDZ were used. The results were also agreed with the findings of other researchers, who reported that TDZ at lower concentration is better than BA, Kinetin or 2iP (Jayanand et al., 2003; Yoshida, 2002 and Anwar et al., 2010).

To expedite still higher number of multiple shoots, it is not advisable to increase TDZ level alone due to inherent problems associated with regeneration. In conjunction with the shoot number, its quality also determines percent rooting response. Quality can be considerably improved by employing a purine cytokinin in combination with TDZ (Briggs et al., 1988). Hence, in the present investigation, efforts were also made to improve the quality of shoots without compromising on its number by supplementing two other cytokinins.

The direct effect of the cytokinin combinations was highly significant and significantly different at different combinations with respect to induction of multiple shoots. The best result obtained was 22.2 shoots at the end of 2 weeks (Table 3 ). The shoots were healthy with completely expanded leaves and elongated well on SEM.

Table.1 Mean number of multiple shoots as influenced by growth regulators with two explants in different cultivars of chickpea

\begin{tabular}{|c|c|c|c|c|c|c|}
\hline Cultivars & \multicolumn{2}{|c|}{ A-1 } & \multicolumn{2}{c|}{ ICCV-2 } & \multicolumn{2}{c|}{ GBS-963 } \\
\hline \multicolumn{1}{|c|}{ Explant } & CN & AME & CN & AME & CN & AME \\
\hline Levels of TDZ & 8.30 & 8.84 & 8.36 & 7.51 & 9.18 & 9.68 \\
Cytokinin combinations & 4.61 & 15.82 & 7.71 & 16.03 & 6.06 & 24.90 \\
\hline
\end{tabular}

Note: (i) Levels of TDZ Vs cytokinin combination: significant in all cultivars

(ii) Explants CN Vs AME: Significant in all cultivars and treatments

Table.2 Effect of levels of TDZ, cytokinin combinations and explant type on multiple shoot production

\begin{tabular}{|c|c|c|}
\hline \multirow{2}{*}{ Growth regulators } & \multicolumn{2}{|c|}{ Mean number of shoots per explant } \\
\hline & Cotyledonary node & Axillary meristem explant \\
\hline SIM1(MS + TDZ : 2iP : KIN :: 4:5:4 $\left.\mu \mathrm{M} \mathrm{L}^{-1}\right)$ & 6.44 & 19.16 \\
\hline SIM2(MS + TDZ : 2iP : KIN $\left.:: 4: 10: 2 \mu \mathrm{M} \mathrm{L}^{-1}\right)$ & 5.26 & 11.16 \\
\hline SIM3 (MS + TDZ : 2iP : KIN :: 4:10:4 $\mu \mathrm{M} \mathrm{L}^{-1}$ ) & 6.13 & 22.41 \\
\hline SIM4 (MS + TDZ : 2iP : KIN :: 8:20:4 $\mu \mathrm{M} \mathrm{L}^{-1}$ ) & 8.90 & 21.48 \\
\hline SIM5 (MS + TDZ : 2iP : KIN :: 8:10:2 $\mu \mathrm{M} \mathrm{L}^{-1}$ ) & 5.71 & 20.48 \\
\hline SIM6 (MS + TDZ : 2iP : KIN :: 4:15:2 $\mu \mathrm{M} \mathrm{L}^{-1}$ ) & 5.53 & 24.57 \\
\hline SIM7 (MS + TDZ : 2iP : KIN :: 16:40:8 $\mu \mathrm{M} \mathrm{L}^{-1}$ ) & 4.86 & 13.90 \\
\hline SIM8 (MS + $\left.0.10 \mathrm{mg} \mathrm{L}^{-1} \mathrm{TDZ}\right)$ & 7.96 & 3.48 \\
\hline SIM9 (MS + $\left.0.15 \mathrm{mg} \mathrm{L}^{-1} \mathrm{TDZ}\right)$ & 9.73 & 5.14 \\
\hline SIM10 (MS + $\left.0.20 \mathrm{mg} \mathrm{L}^{-1} \mathrm{TDZ}\right)$ & 9.55 & 8.21 \\
\hline SIM11 (MS + $\left.0.25 \mathrm{mg} \mathrm{L}^{-1} \mathrm{TDZ}\right)$ & 11.25 & 10.18 \\
\hline SIM12 (MS + $\left.0.45 \mathrm{mg} \mathrm{L}^{-1} \mathrm{TDZ}\right)$ & 6.58 & 10.61 \\
\hline SIM13 (MS + 0.50 $\left.\mathrm{mg} \mathrm{L}^{-1} \mathrm{TDZ}\right)$ & 6.58 & 14.06 \\
\hline
\end{tabular}

Explants:

$\mathrm{S} . \mathrm{Em} \pm \mathrm{CD}$ at $\mathrm{P}=0.01$

Explant x treatments: $\quad 0.176 \quad 0.46$ 
Table.3 Effect of levels of TDZ, cytokinin combinations and three chickpea cultivars on multiple shoot production

\begin{tabular}{|c|c|c|c|}
\hline \multirow{2}{*}{ Growth regulators } & \multicolumn{3}{|c|}{ Mean number of multiple shoots per explant } \\
\hline & A-1 & ICCV-2 & GBS-963 \\
\hline SIM1 & 10.84 & 13.86 & 13.69 \\
\hline SIM2 & 8.34 & 8.06 & 8.24 \\
\hline SIM3 & 12.13 & 14.13 & 16.54 \\
\hline SIM4 & 7.76 & 19.99 & 17.82 \\
\hline SIM5 & 13.03 & 7.32 & 18.94 \\
\hline SIM6 & 11.89 & 11.00 & 22.25 \\
\hline SIM7 & 7.47 & 9.49 & 11.18 \\
\hline SIM8 & 5.55 & 5.73 & 5.89 \\
\hline SIM9 & 7.25 & 7.96 & 7.10 \\
\hline SIM10 & 9.29 & 7.10 & 10.25 \\
\hline SIM11 & 10.73 & 11.45 & 9.98 \\
\hline SIM12 & 8.28 & 6.89 & 10.61 \\
\hline SIM13 & 10.13 & 8.15 & 12.70 \\
\hline S.Em \pm & \multicolumn{3}{|c|}{$\mathrm{CD}$ at $\mathrm{P}=0.01$} \\
\hline 0.0597 & \multicolumn{3}{|c|}{0.158} \\
\hline 0.0488 & \multicolumn{3}{|l|}{0.129} \\
\hline treatment: 0.2153 & \multicolumn{3}{|l|}{0.568} \\
\hline
\end{tabular}

Table.4 Mean number of shoots produced by different cultivars of chickpea with different explants

\begin{tabular}{|c|c|c|c|}
\hline Explant & CN & AME & Mean \\
\hline A-1 & 6.30 & 12.56 & 9.44 \\
ICCV-2 & 8.00 & 12.16 & 10.09 \\
GBS-963 & 7.00 & 17.92 & 12.71 \\
\hline Mean & 7.20 & 14.21 & \\
\hline
\end{tabular}

Cultivar:

S.Em $\quad \mathrm{CD}$ at $\mathrm{P}=0.01$

Explant:

0.0597

0.158

Genotype x Explant: 0.0845

0.129

0.223 
Table.5 Regeneration potentiality of three chickpea cultivars as influenced by explants, growth regulators and their combinations

\begin{tabular}{|c|c|c|c|c|c|c|}
\hline \multirow{3}{*}{$\begin{array}{l}\text { Growth } \\
\text { regulator }\end{array}$} & \multicolumn{6}{|c|}{ Average number of shoots per explant } \\
\hline & \multicolumn{2}{|c|}{ A-1 } & \multicolumn{2}{|c|}{ ICCV-2 } & \multicolumn{2}{|c|}{ GBS-963 } \\
\hline & $\begin{array}{l}\text { Cotyledo } \\
\text { nary node }\end{array}$ & $\begin{array}{l}\text { Axillary } \\
\text { meristem }\end{array}$ & $\begin{array}{l}\text { Cotyledo } \\
\text { nary node }\end{array}$ & $\begin{array}{l}\text { Axillary } \\
\text { meristem }\end{array}$ & $\begin{array}{l}\text { Cotyledo } \\
\text { nary node }\end{array}$ & $\begin{array}{l}\text { Axillary } \\
\text { meristem }\end{array}$ \\
\hline SIM1 & 5.43 & 16.26 & 7.22 & 20.51 & 6.67 & 20.73 \\
\hline SIM2 & 4.48 & 12.20 & 6.00 & 10.12 & 5.30 & 11.17 \\
\hline SIM3 & 4.36 & 19.90 & 8.27 & 20.00 & 5.75 & 27.33 \\
\hline SIM4 & 4.49 & 11.04 & 16.47 & 23.51 & 5.75 & 29.88 \\
\hline SIM5 & 4.76 & 21.30 & 5.75 & 8.90 & 6.63 & 31.25 \\
\hline SIM6 & 4.33 & 19.45 & 5.65 & 16.35 & 6.61 & 37.89 \\
\hline SIM7 & 4.35 & 10.60 & 4.58 & 14.40 & 5.65 & 16.70 \\
\hline SIM8 & 6.605 & 4.50 & 8.35 & 3.10 & 8.93 & 2.85 \\
\hline SIM9 & 8.13 & 6.38 & 11.31 & 4.60 & 9.75 & 4.45 \\
\hline SIM10 & 10.30 & 8.28 & 8.00 & 6.20 & 10.35 & 10.15 \\
\hline SIM11 & 12.05 & 9.40 & 10.36 & 12.55 & 11.35 & 8.60 \\
\hline SIM12 & 6.31 & 10.25 & 6.00 & 7.78 & 7.43 & 13.80 \\
\hline SIM13 & 6.40 & 13.85 & 6.10 & 10.19 & 7.25 & 18.15 \\
\hline ivar $\mathrm{x}$ exp & level c & Z: & $\begin{array}{l}0 . \\
0 . \\
0 .\end{array}$ & $\begin{array}{l}m \pm \\
45 \\
20 \\
49\end{array}$ & $\begin{array}{l}\mathrm{D} \text { at } \mathrm{P}=0.01 \\
804 \\
572 \\
530\end{array}$ & \\
\hline
\end{tabular}

Table.6 Influence of auxin concentration on per cent rooting in three cultivars of chickpea

\begin{tabular}{|l|l|l|l|}
\hline \multicolumn{1}{|c|}{ Auxin concentration } & \multicolumn{1}{|c|}{ A-1 } & \multicolumn{1}{|c|}{ ICCV-2 } & \multicolumn{1}{c|}{ GBS-963 } \\
\hline NAA 2.5 $\mu \mathrm{M}(\mathrm{RIM} 1)$ & $24.7(29.7)$ & $55.8(48.3)$ & $35.0(36.2)$ \\
\hline NAA 5.0 $\mu \mathrm{M}(\mathrm{RIM} 2)$ & $59.5(50.4)$ & $35.0(36.2)$ & $58.6(49.9)$ \\
\hline NAA 7.5 $\mu \mathrm{M}$ (RIM3) & $15.5(23.1)$ & $61.1(51.4)$ & $9.09(17.6)$ \\
\hline
\end{tabular}

Note: Figures in parenthesis indicate transformed values 
Fig.1 Shoot morphogenetic response of three cultivars of chickpea as influenced by kind of explants and growth regulator

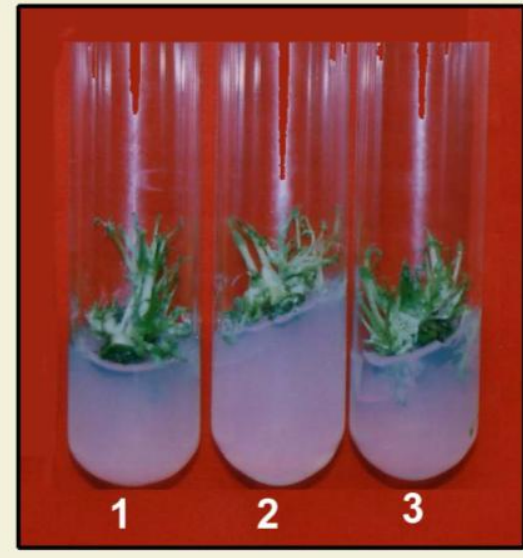

Responce of Cotyledonary node to TDZ

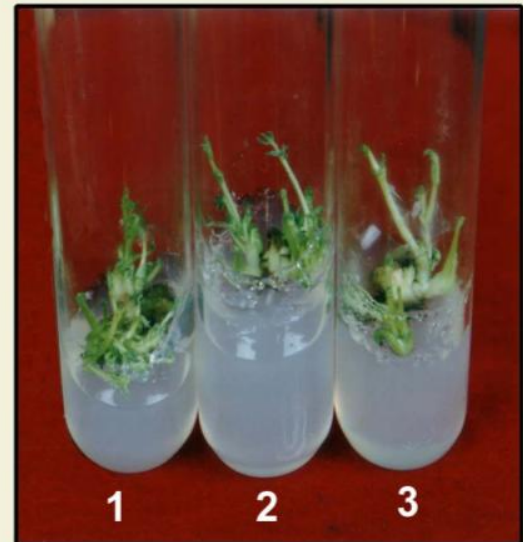

Responce of Cotyledonary node to Cytokinin combination

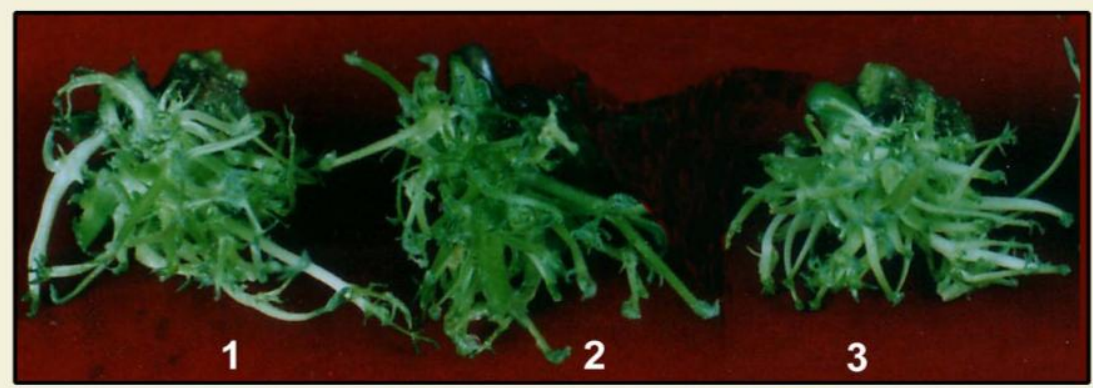

Responce of Axillary meristem explant to TDZ

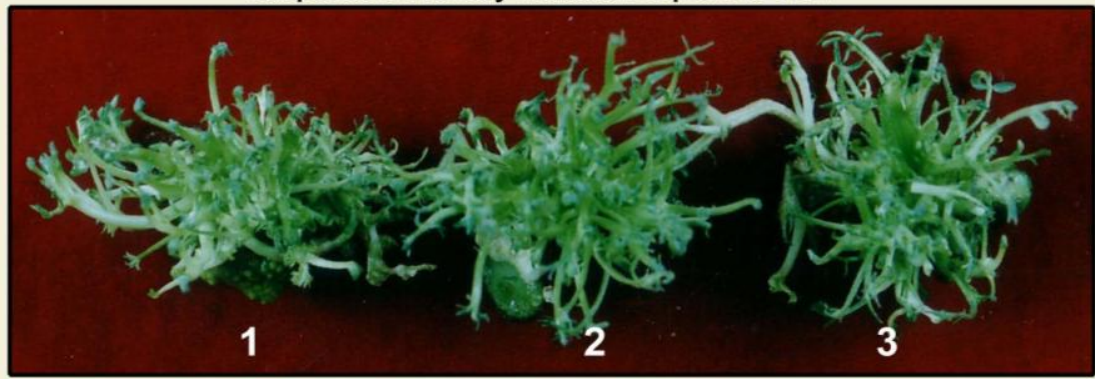

Responce of Axillary meristem explant to Cytokinin combination

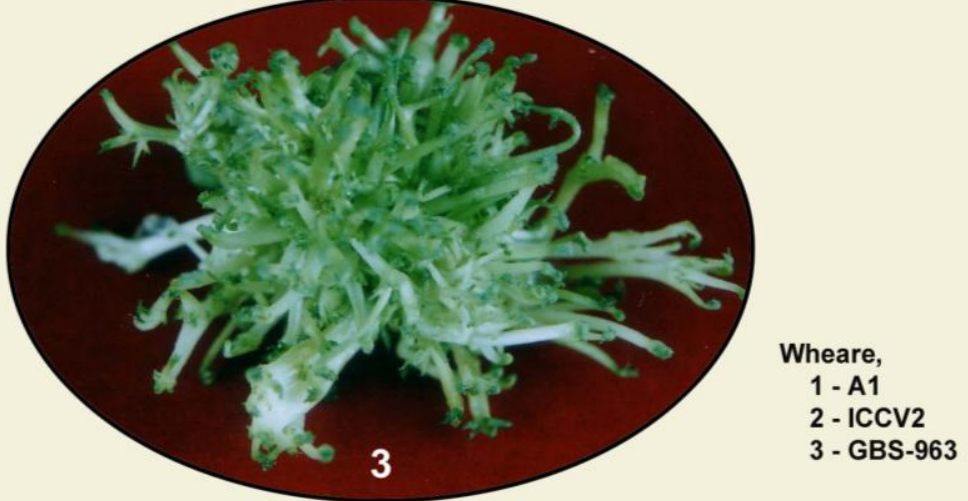

Responce of Axillary meristem explant in cultivar GBS-963 to best Cytokinin combination 


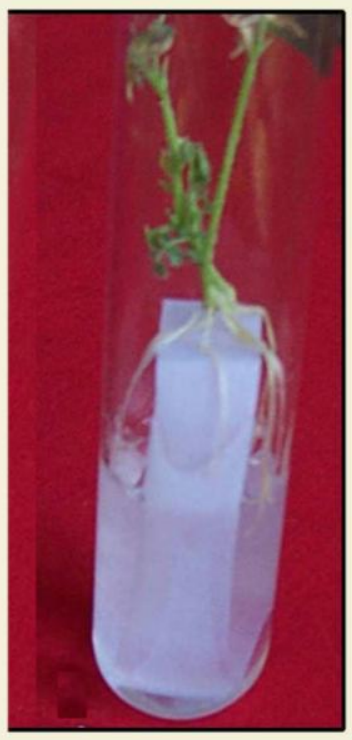

Fig 2: Responce of Chickpea to rooting as influenced by auxin

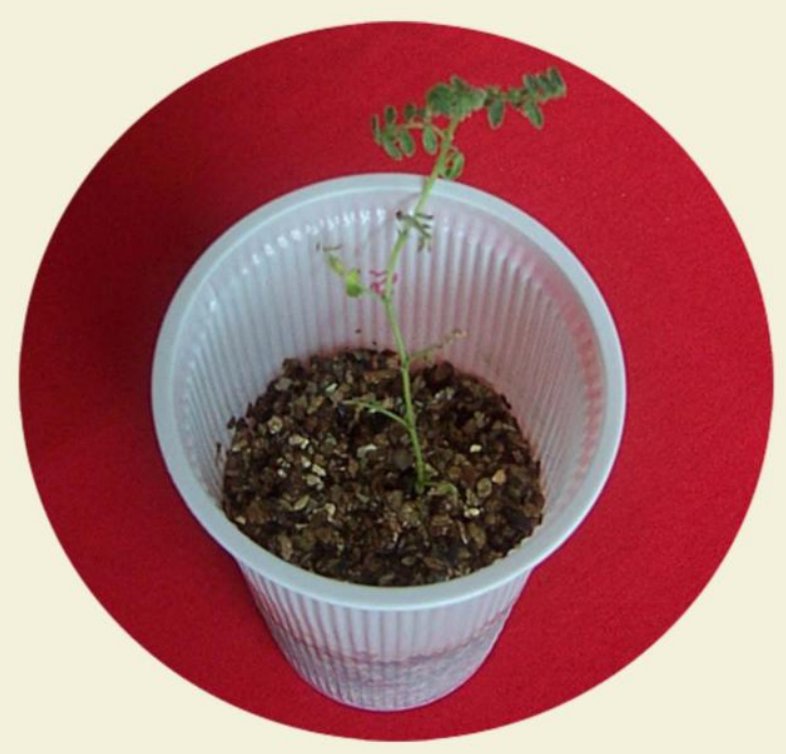

Fig 3: Well established In-vitro generated seedlings in potting medium. 
Therefore, inhibition of shoot elongation by TDZ may be due to its high cytokinin activity and should not be considered as toxic effect. TDZ was found to be advantageous in inducing higher number of adventitious shoots of Pinus strobus but at higher levels of TDZ, was inhibited shoot elongation (Pijut et al., 1991).

\section{Effect of genotype on shoot regeneration response}

Morphogenetic response of many legumes has been shown to be under strict control of the genetic background of the starting material (Malik and Saxena, 1992). Recalcitrance of crop is attributed to genetic differences that generally block the generative process in tissue culture. So in several crops different cultural conditions were found necessary for regenerating different genotypes. These underlined the need for development of an efficient regeneration protocol for a given genotype.

In the present study, significant differences were observed among the three genotypes for their ability to produce multiple shoot buds. Such genotypic differences have been reported by many scientists not only for direct organogenesis (Singh et al., 1997; Altinkut et al., 1997 and Sharma and Amla, 1998) but also for indirect organogenesis (Kumar et al., 1994 and Sagare et al., 1993). The best combination TDZ:2-ip:KIN::4:15:2( $\left.\mu \mathrm{ML}^{-1}\right)$ was identified for the genotype GBS963(22.3), on the contrary, higher levels of growth regulators 8:10:4 and 8:10:2 found to be optimum for ICCV-2 and A-1 respectively (Table 3). Thus, the results suggested that three cultivars differed greatly with respect to their response to the optimum combination of growth regulators (Jayanand et al., 2003) and hence, to exploit full genotypic potentiality of each genotype, optimum concentration of growth regulator needs to be standardized.
This shows that for the given cytokinin, the response an explants and the genotypic performance may differ. The basis of such genotypic differences seems to lie in the difference of endogenous hormone concentrations in the same explant tissues of different genotypes (Altinkut et al., 1997).

\section{Rooting}

Lack of reproducibility of regeneration protocols and highly problematic rooting and subsequent transplantation of the in vitro regenerated shoots is a major limiting factor for obtaining complete transgenic chickpea plants and their progeny. Most of the regeneration protocols in chickpea are genotype specific. In some protocols where, shoots were regenerated successfully, difficulties encountered in obtaining roots on these regenerated shoots (Sagare et al., 1993; Shri and Davis 1992 and Brandt and Hess 1994). In some cases, though rooting was obtained, failure in establishment was reported (Surya-Prakash et al., 1992) but even well rooted and established seedlings exhibited poor survivability (Kumar et al., 1994 and Brandt and Hess 1994). Rhizogenesis (root formation) is controlled by basal medium composition. Another important deciding factor is type and concentration of growth regulator.

The survey of literature indicated that among various auxins, IBA and NAA were most commonly used. The chickpea crop response to NAA and IBA was good as compared to other auxins (Jayanand et al., 2003, Rajendrer-Singh et al., 2002 and Senthil et al., 2004). The rooting response was calculated in terms of varied response exhibited by desi and kabuli group of chickpea cultivars to different levels of NAA (Table 6 and Fig. 2). Compared to desi, kabuli cultivars response was better at little higher concentration of $7.5 \mu \mathrm{M}$ NAA $(51.4 \%)$. On 
the contrary, $5.0 \mu \mathrm{M} / \mathrm{L}$ NAA resulted in higher rooting in A-1 (50.4\%) and GBS-963 (49.9\%). Brandt and Hess (1994) observed differential response for rooting in desi and kabuli cultivars. The plantlets obtained from root induction medium (RIM) had relatively poor root length and shoot growth. Consequent to transfer to Arnon's nutrient medium for about 10-15 days, resulted in increased shoot and root growth and production of lateral roots with new leaf growth. Hence, it has been suggested that Arnon's liquid culture is important in developing roots from plantlets derived from in vitro culture and further, to facilitate better establishment of plantlets.

\section{Hardening and establishment of plantlets}

Next hurdle for getting regenerated plantlets is hardening. Hence, this phase forms another important step which takes into account of potting medium, temperature, humidity, light intensity and photoperiod. Among various potting media viz., vermiculite, peat, medium sand, soil + sand, only vermiculite proved to be moderately successful with $30-43.3 \%$ survival. Initially, they were maintained at $22+2^{0} \mathrm{C}$ and a night temperature of $17+1^{0} \mathrm{C}$. Fifteen days after transplantation, temperature was increased to $25+3^{0} \mathrm{C}$ and $17+1^{0} \mathrm{C}$ for day and night, respectively. The next factor, humidity, also plays a crucial role in the hardening process. The plants were initially maintained at high humidity of $90 \%$ by covering it with polypropylene bags and then slowly acclimatized to the ambient humidity by gradually opening the cover. The plants were maintained at a light intensity of 25003500 lux up to rooting stage. Where as, the entire hardening process was carried out at a light intensity of 10,000-12,000 lux (Fig. 3). In general, chickpea is found to be very sensitive to the irrigation process. Optimal moisture was maintained by adding water as and when required. From the it is clear that, for successful hardening and transplantation procedure, meticulous observation of the morphology of leaf size, color, stem inter nodal length and the root system growth is very much necessary.

\section{References}

Aasim, M., Khawar, K.M., Özcan, S. 2010. Efficient in vitro propagation from preconditioned embryonic axes of Turkish cowpea (Vigna unguiculata L.) Cultivar akkiz. Arch. Biol. Sci. 62:1047-1052.

Altinkut, A., Bajrovic, K. and Gozukirmizi, N., 1997. Regeneration and hairy root formation of chickpea using callusderived plantlets and seedlings. International Chickpea Newsletter. 4: 30-31.

Anwar, F., Sharmila, P. Saradhi, P. 2010. No more recalcitrant: Chickpea regeneration and genetic transformation. Afri. J. Biotechnol., 9(60): 782-797.

Brandt, E. B. and Hess, D., 1994. In vitro regeneration and propagation of chickpea (Cicer arietinum) from meristem tips and cotyledonary nodes. In vitro Cell Development Biology, 30(1): 75-80.

Briggs, B. A., Mccullouds, S. M. and Edick, L. A., 1988. Micropropagation of azaleas using thidiazuron. Acta Horticulturae. 226: 205-208.

Burkhanova, E. A., Fedina, A. B., Baskakar, Y. U. A. and Kulaeva, D. N. 1984. Comparative study of the actions of 6benzylaminopurine, thidiazuron and cartoon on growth of intact pumpkin seedlings. Soviet Plant Physiology. 31: 8-12.

Fitch, M. M. M. and Moore, P. H., 1990. Comparison of 2, 4-D and picloram for selection of longterm totipotent green callus cultures of sugarcane. Plant Cell, Tissue and Organ Culture, 20: 157-163. 
Fontana, G. S., Santini, L., Caretto, S., Frugis, G., Hariotti, D. 1993. Genetic transformation in the grain legume Cicer ariteinum L. Plant Cell Reports 12: 194-198.

Gomez, K. A. and Gomez, A. A. 1984. Statistical Procedures for Rice Research Workers. Publication by International Rice Research Institute, Manila, Phillippines, pp.196-211.

Jayanand, B., Sudarsanam, G., Sharma, K. K., 2003. An efficient protocol for the regeneration of whole plant of chickpea by using axillary meristem explants derived from in vitro germinated seedlings. In vitro Cell Division and Biology, 39: 171-179.

Jodha, N. S. and Subbarao, K. V., 1987. Chickpea: world importance and distribution. In: Saxena, M. C. and Singh, K. B., eds. The chickpea. Wallinford, UK: Cab international, 1-10

Kar, S., Basu, D., Das, S., Ramkrishan, N. A., Mukherjee, P., Nayak, P., Sen, S. K., 1997. Expression of CryIAc gene of Bacillus thuringiensis in transgenic chickpea plants inhibits development of pod-borer (Heliothis armigera) larvae. Transgenic Research, 6 (2): 177-185.

Kartha, K. K., Patil, K. and Lung, N. L., 1981. Plant regeneration from meristems of grain legumes: Soybean, Cowpea, Peanut, Chickpea and Bean. Canadian Journal of Botany, 59: 16711679.

Krishnamurthy, K. V., Suhasini, K., Sagare, A. P., Meixner, M., De-Kathen, A., Pickardt, T. and Schieder, 2000. Agrobacterium mediated transformation of chickpea (Cicer arietinum L.) embryo axes. Plant Cell Reports, 19 (3): 235-240.

Kumar, D. V., Kirti, P. B., Sachan, J. K., Chopra, V. L., 1994. Plant regeneration via somatic embryogenesis in chickpea. Plant Cell Reports, 13: 468-472.
Malik, K. A. and Saxena, P. K., 1992. Thidiazuron induces high-frequency shoot regeneration in intact seedlings of pea (Pisum sativum), chickpea (Cicer arietinum) and lentil (Lens culinaris). Australian Journal of Plant Physiology 19: 734-740.

Murthy, B. N. S., Victor, J., Singh, R. P., Fletcher, R. A. and Saxena, P. K., 1996. In vitro regeneration of chickpea (Cicer arietinum L.) stimulation of direct organogenesis and somatic embryogenesis by thidiazuron. Plant Growth Regulation, 19: 233-240.

Pijut, P. M., Michler, C. H. and Voelker, T. M., 1991. Effects of embryo explant orientation, thidiazuron and agar on eastern white pine adventitious shoot initiation. In: Proceedings of International Symposium on Application of Biotechnology to Tree Culture - Protection and Utilization, Columbus, p.126.

Rajendrer-singh, Jat, R. S., Sahoo, P. D., Srinivasan and Singh, R., 2002. Thidiazuron induced multiple shoot formation in chickpea (Cicer arietinum L.). Journal of Plant Biochemistry and Biotechnology, 11 (2): 129-131.

Rekha, K. T. and Thiruvengadam, M., 2009. An efficient micro-propagation of chickpea (Cicer arietinum L.). The Philippine Agricultural Scientist, 92(3): 320-326.

Rozan Al-Tanbouz and Hassan Abu-Qaoud, 2016. In vitro Regeneration of Chickpea (Cicer arietinum L.). Plant Cell Biotechnology and Molecular Biology, 17(1\&2): 21-30.

Sagare, A. P., Suhasini, K. and Krishnamurthy, K. V., 1993. Plant regeneration via somatic embryogenesis in chickpea (Cicer arietinum L.). Plant Cell Reports, 12 (11): 652-655.

Saxena, P. K., Malik, K. A. and Gill, R., 1992. Induction by thidiazuron somatic 
embryogenesis in intact seedlings of peanut. Planta, 187: 421-424.

Saxena, P. K., Malik, K. A. and Gill, R., 1992. Plant regeneration via somatic embryogenesis in intact seedlings of peanut. Planta, 187:421-424.

Senthil, G., Williamson, B., Dinkins, R. D. and Ramsay, G., 2004. An efficient transformation system for chickpea (Cicer arietinum). Plant Cell Report, 23: 297-303.

Sharma, L. and Amla, D. V., 1998. Direct shoot regeneration in chickpea (Cicer arietinum L.). Indian Journal of Experimental Biology, 36 (6): 605-609.

Shri, P. V. and Davis, T. M., 1992. Zeatininduced shoot regeneration from immature chickpea (Cicer arietinum L.) cotyledons. Plant Cell, Tissue and Organ Culture, 28: 45-51.

Singh, A., Singh, N. P. and Asthana, A. N. 1997. Callus induction and direct regeneration from immature embryo in chickpea. International Chickpea and
Pigeonpea Newsletter, 4: 39-40.

Singh, N., Kataria, N., 2012. Role of potassium fertilizer on nitrogen fixation in Chickpea (Cicer arietinum L.) under quantified water stress. Journal of Agricultural Technology, 8(1): 377-392.

Sundararaj, N. and Nagaraju, S., 1968. Design and Analysis of Field Experiments, University of Agricultural Sciences, Hebbal, Bangalore.

Surya-prakash, Chowdhury, J. B., Jain, R. K. and Chowdhury, V. K., 1992. Factors affecting plant regeneration in chickpea. Indian Journal of Experimental Biology, 30: 1149-1153.

Varga, V. D., Ornjanov, V. and Torbica, V. 1990. Plant regeneration from peach cotyledons. Jugsol Vocarstya, 24: 374114.

Yoshida, T. 2002. Adventitious shoot formation from hypocotyls sections of mature soybean seeds. Breed. Sci., $52: 1-8$.

\section{How to cite this article:}

Suma S. Biradar, O. Sridevi, P.M. Salimath, P.U. Krishnaraj, S.A. Desai, V. Rudra Naik, Guruprasad Hiremath and Veeresha, B.A. 2017. Chickpea: No More a Recalcitrant Species for in vitro Regeneration Response. Int.J.Curr.Microbiol.App.Sci. 6(12): 53-65.

doi: https://doi.org/10.20546/ijcmas.2017.612.007 